\title{
Restless legs syndrome: differential diagnosis and management with pramipexole
}

REVIEW

\author{
This article was published in the following Dove Press journal: \\ Clinical Interventions in Aging \\ 17 June 2009 \\ Number of times this article has been viewed
}

\section{Francesca Brindani \\ Francesca Vitetta \\ Franco Gemignani}

Department of Neurosciences, University of Parma, Italy
Correspondence: Franco Gemignani Department of Neurosciences, University of Parma, Italy Tel +39052I 704 II 5

Fax +39 052I 704 II5

Email franco.gemignani@unipr.it
Abstract: Restless legs syndrome (RLS) is a condition characterized by discomfort at rest and urge to move focused on the legs. RLS may occur as an idiopathic, often hereditary condition (primary RLS), or in association with medical conditions (secondary RLS) including iron deficiency, uremia, and polyneuropathy. Current understanding of the pathophysiology of RLS points to the involvement of three interrelated components: dopaminergic dysfunction, impaired iron homeostasis, and genetic mechanisms. The diagnosis of RLS is made according to the consensus criteria by a National Institutes of Health panel: 1) an urge to move the legs, usually accompanied by uncomfortable sensations; 2) beginning or worsening during rest; 3 ) relieved by movement; and 4) worse, or only occurring, in the evening or at night. The differential diagnosis of RLS aims to: 1) distinguish RLS from other disorders with RLS-like symptoms and 2) identify secondary forms, with investigation of underlying diseases. The treatment of RLS demands a clinical evaluation to rule out and cure causes of secondary RLS, including iron supplementation when deficient, and to eliminate the triggering factors. The presence of neuropathy should be especially investigated in nonhereditary, late-onset RLS, in view of a possible treatment of the underlying disease. The first line treatment for idiopathic RLS is represented by dopamine agonists, in particular nonergot-derived ropinirole and pramipexole, whereas ergot dopamine agonists (cabergoline and pergolide) are no longer in first-line use given the risks of cardiac valvulopathy. Although no comparative trials have been published, a meta-analysis of pramipexole versus ropinirole suggests differences in efficacy and tolerability favoring pramipexole.

Keywords: restless legs syndrome, pramipexole, dopamine, agonists, small fiber neuropathy

\section{Introduction}

Restless legs syndrome (RLS) is a common, yet overlooked condition, mainly characterized by discomfort at rest and urge to move focused on the legs, first described by Willlis $^{1}$ in 1672 , and recently re-defined by consensus criteria put forth by a National Institutes of Health (NIH) panel. ${ }^{2}$

Most of the epidemiological studies that have employed adequate diagnostic criteria $^{3}$ report prevalences of RLS (men and women combined) between $6 \%$ and $12 \%,{ }^{4}$ when conducted in Western populations, but when distinguishing between the mere presence of RLS and clinically significant RLS (with symptoms frequent or severe enough to require treatment), the prevalence of this latter approaches $3 \%{ }^{5}$ The prevalence of RLS is distinctly lower in Asian populations, ranging from $0.1 \%$ in Singapore ${ }^{6}$ to $4.6 \%$ in elderly Japanese. ${ }^{7}$

RLS may occur as an idiopathic, often hereditary condition (primary RLS), or in association with several medical conditions (secondary RLS) such as iron deficiency, ${ }^{8}$

submit your manuscript $\mid$ www.dovepress.com 
end-stage renal diseases,${ }^{9}$ pregnancy, ${ }^{10}$ rheumatologic disorders, ${ }^{11,12}$ diabetes, ${ }^{13,14}$ as well as neurologic conditions such as Parkinson's disease, ${ }^{15}$ spinal cord lesions, ${ }^{16}$ multiple sclerosis, ${ }^{18}$ and polyneuropathy. ${ }^{18}$

The association of RLS with polyneuropathy is of particular interest from epidemiological, mechanistic, and diagnostic viewpoints, but is still controversial, in spite of extensive studies. Prevalence estimates of RLS in neuropathy are extremely variable, ranging from $5.2 \%{ }^{19}$ to $54 \%{ }^{20}$ In a series of 104 consecutive patients with miscellaneous neuropathies, we found a $29 \%$ prevalence of RLS, compared to $9 \%$ in controls. ${ }^{18}$ A prevalence of RLS of $54 \%$ was found in a selected series of patients with neuropathy with symptoms of pain or dysesthesia. ${ }^{20}$ On the contrary, in a recent controlled, double-blind study, the prevalence of RLS in neuropathy patients $(12.2 \%)$ did not differ significantly from controls $(8.2 \%)$, but in the subgroup of patients with hereditary neuropathy a higher prevalence of $19.4 \%$ was found. ${ }^{21}$ Conflicting results may be due to methodological discrepancies in the design of the studies and in the assessment of RLS and of neuropathy, and variations in etiology of neuropathy between cohorts; in addition, it should be considered that, as polyneuropathy is usually an evolutive condition, the appearance or disappearance of RLS may be related to different phases of the disease. As it has been shown that RLS can be triggered by small fiber sensory neuropathy, ${ }^{18,22-24}$ it is expected that RLS prevalence in neuropathy will be higher when considering the forms with prevailing small fiber involvement, such as diabetic neuropathy. ${ }^{14,25}$ In conclusion, we think that the prevalence of RLS in the course of polyneuropathy should be further assessed separately in different subtypes, segregated either by etiology or on the basis of preferentially involved nerve fiber population.

Current understanding of the pathophysiology of RLS points to the involvement of three interrelated components: dopaminergic dysfunction, impaired iron homeostasis, and genetic mechanisms. ${ }^{26}$ In particular, dopamine dysfunction plays a central role, as suggested by the early observation that dopaminergic drugs are highly effective in treating RLS. ${ }^{27}$ Increasing data support the hypothesis that dysfunctioning dopaminergic pathway resides in the small diencephalospinal tract originating from the hypothalamic A11 nucleus, ${ }^{16}$ modulating the excitability of sensorimotor spinal circuits presumably subserving RLS. ${ }^{28,29}$ Dysfunction of endogenous opioidergic circuits, possibly mediated by an interaction with the dopaminergic system, has been also implicated, based on the positive clinical response to opioidergic agents. ${ }^{30}$ Recently, in a PET study with an aspecific opioid receptor ligand, von Spiczak and colleagues found a negative correlation between RLS severity and the ligand binding in thalamus, amygdale, and anterior cingulated gyrus, structures involved in the medial pain system. ${ }^{31}$

Alterations in iron metabolism probably intersect with dopamine signaling, for instance as a consequence of the role of iron as cofactor for tyrosine hydroxylase. ${ }^{8}$ Further, dopaminergic transmission may be affected by genetic factors, which however may also influence RLS at different neural levels, underlying changes of other motor and/or sensory structures possibly implicated in RLS. ${ }^{29}$ Finally, abnormal hyperexcitability of spinal circuits in RLS could be induced not only by impaired descending dopaminergic modulation, but also by changes in the spinal cord itself, ${ }^{28}$ or by abnormal peripheral inputs in peripheral nervous system (PNS) diseases. ${ }^{18}$

\section{Diagnosis}

The diagnosis of RLS is made according to the NIH criteria, ${ }^{2}$ that is: 1) an urge to move the legs, usually accompanied or caused by uncomfortable or unpleasant sensations in the legs; 2 ) beginning or worsening during periods of rest or inactivity such as lying or sitting; 3) partially or totally relieved by movement such as walking or stretching; 4) worse in the evening or at night than during the day, or only occurring in the evening or night. In addition, supportive clinical features are considered (Table 1), which include, besides positive family history and response to dopaminergic therapy, the occurrence of periodic limb movements (PLMs) during wakefulness or sleep. PLMs are stereotyped rhythmic movements characterized by extension of the big toe and dorsiflexion of the ankle, which are recorded in standard polysomnography by surface electromyogram of anterior tibialis. ${ }^{32}$ A pathological number of PLMs ( $>5$ PLMs/hour of sleep) is found in about $80 \%$ of RLS patients. ${ }^{33}$ and correlates with RLS severity. ${ }^{34,35}$ PLMs, however, are not specific for RLS, occurring in a variety of sleep disorders and also in normal people. PLMs can be a useful second level diagnostic tool in selected patients with uncertain RLS diagnosis who deserve instrumental investigations.

The diagnostic criteria have been summarized in a comprehensive definition of RLS as "movement-responsive quiescegenic nocturnal focal akathisia usually with dysesthesias". 36

There are two major steps in the differential diagnosis of RLS: 1) distinguishing RLS from other disorders with RLS-like symptoms; and 2) the individuation of secondary forms, with investigation of underlying diseases. 
Table I NIH diagnostic criteria of RLS

\section{Essential criteria}

I. An urge to move the legs, usually accompanied or caused by uncomfortable or unpleasant sensations in the legs.

2. The urge to move or unpleasant sensations begin or worsen during periods of rest or inactivity such as lying or sitting.

3. The urge to move or unpleasant sensations are partially or totally relieved by movement, such as walking or stretching, at least as long as the activity continues.

4. The urge to move or unpleasant sensations are worse in the evening or night than during the day or only occur in the evening or night.

Supportive clinical features

I. Positive family history of RLS.

2. Response to dopaminergic therapy.

3. Periodic limb movements during wakefulness or sleep (PLMs)*.

Associated features

I. Natural clinical course: Onset age is variable, in patients with earlier onset ( $<50$ years) the symptoms are insidious, while patients with later onset have a more aggressive course. RLS is usually a chronic disease with progressive clinical course; in mildest forms of RLS the clinical course can be static or intermittent.

2. Sleep disturbances: disturbed sleep is usually associated to RLS, this morbidity is however aspecific.

3. Medical evaluation/Physical examination: physical and neurological examination is generally normal (except for secondary RLS). Medical evaluation should be addressed to possible causes for secondary RLS.

Abbreviations: NIH, National Institutes of Health; PLMs, periodic limb movements; PLMW, periodic limb movement during wakefulness; RLS, restless legs syndrome.

Conditions that resemble RLS (RLS "mimics") include those with motor restlessness and those with a variety of leg pains or discomfort. ${ }^{36}$ Motor restlessness is characteristic for neuroleptic-induced akathisia, which, however, is usually generalized, with more stereotyped body and limb movements, while in RLS there is an urge to move a particular part of the body; patients with neurolepticinduced akathisia do not experience sensory discomfort as an antecedent to motor restlessness, and often have no relief by movement. Nocturnal leg cramps are relieved with stretching or walking, but no urge to move is experienced, and painful muscular contraction is clearly unlike RLS sensations. Positional discomfort comes on with prolonged sitting or lying in the same position, but it is usually relieved by a simple change in position, unlike RLS, without a true circadian pattern, if not because during the night the rest increases the chances to maintain the same position. Volitional movements such as foot tapping and leg rocking, occurring in conditions of uneasiness, usually are not associated with sensory symptoms, discomfort, or conscious urge to move. Painful legs and moving toes involve mainly feet and toes, with slow writhing movements, in the absence of either conscious urge to move or circadian pattern. Various painful conditions, neurological or nonneurological, such as myelopathy, radiculopathy, peripheral neuropathy, lower limb arthritis, nighttime pain in the lower limbs in the course of congestive heart failure, may have symptoms that are worse at night, and cause sleep disturbances, but there is no urge to move and relief by movement.
The diagnosis of RLS secondary to, or associated with, other conditions represents a double-faceted process, as the problem may consist in the individuation of occult causes of apparently idiopathic RLS, or, on the contrary, in the recognition of overlooked RLS symptoms in the context of an overt neurological or systemic disease. The first occurrence is exemplified by an undisclosed iron deficiency, or by a mild neuropathy mainly manifesting with RLS; on the contrary, in the clinical context of severe diseases such as uremia, Parkinson disease, or multiple sclerosis, RLS may be disregarded in spite of its significant contribution to poor quality of life.

The role of polyneuropathy and its diagnostic work-up in RLS is controversial, in view of the uncertainty about its epidemiology, as discussed above. Although a statistically significant association of RLS with polyneuropathy has not been clearly demonstrated in overall populations of neuropathy, several reports suggest that RLS is frequent in distinct forms of polyneuropathy, especially when involving small sensory fibers, ${ }^{37}$ and this should be considered in a diagnostic approach.

As a practical point, patients with apparently idiopathic RLS of late onset and nonfamilial should be screened for polyneuropathy, especially when characterized by a sensory phenotype, and in particular for symptoms and signs of the small fiber series, and for possible causes of polyneuropathy if appropriate; on the other hand, we suggest that patients with polyneuropathy, especially of sensory type, should be questioned for symptoms of RLS as a treatable manifestation of the disease. 


\section{Treatment}

The treatment of RLS firstly demands a thorough clinical evaluation to rule out causes of secondary RLS, the most common of which is iron deficiency, and to eliminate the triggering factors, if any. A recommendation should be made to investigate the presence of neuropathy in selected cases, especially in nonhereditary, late-onset RLS, and/or in the presence of prominent sensory symptoms, in view of a possible treatment of the underlying condition, besides symptomatic therapy of RLS. It would be interesting that future trials explored if RLS associated with polyneuropathy and/or with sensory phenotype will preferentially respond to particular drugs, such as antiepileptic drugs, rather than to dopaminergic therapy, ${ }^{38}$ as previously suggested. ${ }^{23}$

For primary RLS there are no treatments modifying the course of the disease available and the goal of different therapeutic strategy is to control the symptoms.

The European Federation of Neurological Sciences (EFNS) task force ${ }^{39}$ performed a review of the literature up to 2004 for the drug classes and interventions employed in the treatment of RLS and put forth guidelines for the management of RLS. According to EFNS guidelines, level A recommendations (effective in relieving the symptoms), were offered for cabergoline, gabapentin, pergolide, ropinirole, levodopa, and rotigotine by transdermal delivery, whilst other dopamine agonists (pramipexole, bromocriptine), valproate, oxycodone, carbamazepine, and clonidine were evaluated as probably effective (level B rating).

More recently, a task force commissioned by the Movement Disorder Society (MDS) performed an evidence-based review of the medical literature, which included studies published before December 31, 2006. ${ }^{30}$ The following drugs were considered efficacious: levodopa, ropinirole, pramipexole, cabergoline, pergolide, and gabapentin. Rotigotine, bromocriptine, oxycodone, carbamazepine, valproic acid, and clonidine were considered likely efficacious. Drugs that were considered investigational included dihydroergocriptine, lisuride, methadone, tramadol, clonazepam, zolpidem, amantadine, and topiramate, as well as magnesium, folic acid, and exercise. Intravenous iron dextran resulted likely efficacious for the treatment of RLS secondary to end-stage renal disease and investigational in RLS subjects with normal renal function, whereas oral iron was considered investigational, depending on the iron status of subjects.

According to both EFNS and MDS guidelines, the first line treatment for idiopathic RLS is represented by drugs that enhance dopaminergic neurotransmission.

\section{Dopaminergic agents}

\section{L-Dopa/Benserazide or L-Dopa/Carbidopa}

L-Dopa/Benserazide or L-Dopa/Carbidopa (100/25 mg or 200/50 $\mathrm{mg}$ at bedtime) are efficacious in controlling sensory and motor symptoms. As a consequence of its short plasma half-life (1-2 hours) there is a rapidly decreasing effect and RLS may reappear in the second half of the night, so that a second dose may be needed, usually three hours after bedtime. ${ }^{35}$

The limitation of L-Dopa consists mainly in the phenomenon of "augmentation", a condition characterized by the worsening of RLS severity during RLS treatment. ${ }^{40}$ Diagnostic criteria for augmentation are shown in Table 2.

Prevalence of augmentation ranges from $18.6 \%$ to $72 \%{ }^{34,35}$ and seems to be more frequent with higher doses and longer treatment duration. ${ }^{36}$ Dosages of $300-400 \mathrm{mg}$ should not be exceeded.

Because of augmentation and the difficulty in controlling symptoms for the whole night in severe RLS (even with the combination of standard and sustained release formulation), L-Dopa is best used in patients with mild RLS or intermittent symptoms.

Since the use of L-Dopa is limited by its pharmacokinetic and pharmacodynamic characteristic, there has been a growing interest towards dopamine agonists.

\section{Ergot-derived}

Pergolide and cabergoline are effective in RLS in doses of $0.4-0.55 \mathrm{mg}$ and $0.5-3 \mathrm{mg}$, respectively. ${ }^{34}$ However, because of their potential to induce fibrotic side effects with cardiac valvulopathy, they are not recommended in first-line use in RLS treatment and, if used, cardiopulmonary monitoring is required. There is insufficient evidence to make recommendation about bromocriptine, $\alpha$-dihydroergocriptine, and lisuride. ${ }^{30}$

\section{Nonergot-derived}

Extensive data are available for ropinirole and pramipexole, which have approval for the indication idiopathic RLS in USA and European Union, whereas for rotigotine, although likely effective, more studies are needed. Rotigotine, formulated as a silicone-based transdermal patch (1-3 mg/24 h), improved the symptoms of RLS in two six-month trials in adults with idiopathic, moderate to severe RLS. Transdermal rotigotine was generally well tolerated, and improvements in RLS symptoms have been maintained in the long term. Further evaluations are required to ascertain if continuous 
Table 2 Augmentation diagnostic criteria

A. Basic features (all need to be met)

I. The increase in symptom severity was experienced on five out of seven days during the previous week.

2. The increase in symptom severity is not accounted for by other factors such as a change in medical status, lifestyle or the natural progression of the disorder.

3. It is assumed that there has been a prior positive response to treatment.

$B$ and C. Additional features (one or both need to be met)

B. Persisting (although not immediate) paradoxical response to treatment: RLS symptom severity increases some time after a dose increase and improves some time after a dose decrease.

\section{Earlier onset of symptoms:}

I. An earlier onset of at least four hours

or

2. An earlier onset (between two and four hours) occurs with one of the following compared to symptoms status before treatment:

a. Shorter latency to symptoms when at rest;

b. Extension of symptoms to other body parts;

c. Greater intensity of symptoms (or increase in periodic limb movements if measured by polysomnography (PSG) or the suggested immobilization test (SIT);

d. Shorter duration of relief from treatment.

Abbreviation: RLS, restless legs syndrome.

dopaminergic stimulation has the effect of limiting or preventing augmentation.

Ropinirole was effective in improving the symptoms of RLS, compared with placebo, in patients with moderateto-severe primary RLS, with significant improvements observed within two nights of treatment, ${ }^{41}$ and was generally well tolerated. Significant benefits on objective measures of RLS motor symptoms, such as periodic leg movements, and on subjective measures of sleep were also demonstrated.

The main difference between the two drugs seems to reside in earlier efficacy of pramipexole, evident after a single night dose. ${ }^{43}$ Although no comparative trials have been published, a recent meta-analysis of pramipexole versus ropinirole suggested differences in efficacy and tolerability favoring pramipexole. ${ }^{44}$ The indirect comparison showed a superior reduction in the mean International RLS Study Group Rating scale score, higher Clinical Global Impressions - Improvement scale response rate and significantly lower incidence of nausea, vomiting, and dizziness for pramipexole compared to ropinirole.

\section{Pramipexole}

Pramipexole, a nonergoline dopamine agonist with a high selectivity for $\mathrm{D}(2)$ and $\mathrm{D}(3)$ receptors, is the last drug licensed for RLS treatment. Its efficacy was first tested in small or uncontrolled trials, ${ }^{46-49}$ and further confirmed in more extensive studies, as summarized in Table 3 .

Pramipexole improves both subjective symptoms of RLS $^{50-52}$ and objective sleep parameters. ${ }^{53}$ In a doubleblind, randomized, placebo-controlled, fixed-dose trial on 344 patients, ${ }^{50}$ and in double-blind, randomized, placebo-controlled, flexible-dose trial $(0.125 \mathrm{mg} ; 0.25 ; 0.50$; 0.75 ) on 345 patients, ${ }^{51}$ pramipexole improved significantly RLS severity and subjective sleep quality. In a polysomnographic double-blind, randomized, placebo-controlled study on 109 RLS patients (PRELUDE), ${ }^{53}$ pramipexole significantly reduced Periodic Limb Movements during time in bed Index (PLMI) and, at the dose of $0.50 \mathrm{mg}$, improved sleep efficiency (SE) and total sleeping time (TST).

Efficacy of pramipexole was demonstrated either after a single night dose, ${ }^{43}$ or in long-term therapy. ${ }^{54,55}$ Manconi and colleagues, ${ }^{43}$ in a single-blind, randomized, placebocontrolled study, compared subjective and polysomnographic parameters at the baseline and after one night on pramipexole at a single dose of $0.25 \mathrm{mg}$. They found a highly significant reduction in VAS score and a significant reduction of PLMS index (the primary outcome measure), and increment of sleep stage 2 , sleep efficacy and time in bed on the pramipexole night.

Long-term efficacy has been recently confirmed in an open-label trial on 107 patients lasting 26 weeks (PRELUDE-extension) ${ }^{54}$ and in a telephone interview study on 195 RLS patients who took pramipexole at variable doses $(0.125-2.25)$ for at least one year. ${ }^{55}$ In a withdrawal trial, Trenkwalder and colleagues ${ }^{56}$ demonstrated very significant worsening of subjective RLS parameters in the group who discontinued pramipexole after six months of therapy. They also found an elevated number of dropouts $(65 \%)$ in the placebo group, mainly due to lack of efficacy, compared to the drug group (9\%).

Pramipexole is usually well tolerated. The discontinuation rate, about $20 \%$, was similar in all the examined studies. 
Table 3 Pramipexole trials in RLS

\begin{tabular}{|c|c|c|c|}
\hline & Study design & $\begin{array}{l}\text { Pramipexole } \\
\text { administration }\end{array}$ & Outcome measure \\
\hline Partinen $2006^{53}$ & $\begin{array}{l}\text { - Multicenter, double-blind, randomized, } \\
\text { fixed-dose, placebo-controlled trial } \\
\text { - Randomization: } 1: 1: 1: 1: 1 \\
\text { - } 109 \text { patients with moderate-severe } \\
\text { idiopathic RLS } \\
\text { - Three week period }\end{array}$ & $\begin{array}{l}\text { - Fixed doses: } \\
-0.125 \mathrm{mg} \\
-0.25 \mathrm{mg} \\
-0.50 \mathrm{mg} \\
-0.75 \mathrm{mg} \\
\text { - } 2-3 \text { hours before } \\
\text { bedtime }\end{array}$ & $\begin{array}{l}\text { - Primary outcome: PLMI } \downarrow \\
\text { - Secondary outcome: } \\
\text { PLMSI } \downarrow ; \text { PLMWI } \downarrow ; \text { PLM } \downarrow ; \text { SL } \downarrow ; \text { time } \\
\text { in delta sleep } \downarrow \\
\text { PLMAI } \rightarrow \text { SE } \rightarrow \text {;SST } \rightarrow \\
\text { IRLS } \downarrow ; \text { ESS } \rightarrow \text { SSQ } \uparrow ; \text { SF-36 } \uparrow \\
\text { (improvement in social function sub- } \\
\text { score); PGI } \uparrow \text { CGI } \uparrow\end{array}$ \\
\hline $\begin{array}{l}\text { Winkelman } \\
2006^{50}\end{array}$ & $\begin{array}{l}\text { - Double-blind, randomized, fixed-dose, } \\
\text { placebo-controlled trial } \\
\text { - Randomization: I:I:I:I } \\
\text { - } 344 \text { patients with moderate-severe } \\
\text { idiopathic RLS } \\
\text { - } 12 \text { week period }\end{array}$ & $\begin{array}{l}\text { - Fixed doses: } \\
-0.25 \mathrm{mg} \\
-0.50 \mathrm{mg} \\
-0.75 \mathrm{mg} \\
\text { - } 2-3 \text { hours before } \\
\text { bedtime }\end{array}$ & $\begin{array}{l}\text { - Primary outcome: IRLS } \downarrow \\
\text { - Secondary outcome: } \\
\text { Improvement in PGI, CGI,VAS, ESS, } \\
\text { RLS-QOL. }\end{array}$ \\
\hline Oertel $2007^{51}$ & $\begin{array}{l}\text { Double-blind, randomized, flexible-dose, } \\
\text { placebo-controlled trial. } \\
\text { - Randomization: (placebo:pramipexole = I:2) } \\
\text { - } 345 \text { patients with moderate-severe idi- } \\
\text { opathic RLS } \\
\text { - Six week period }\end{array}$ & $\begin{array}{l}\text { - Starting dose }=0.125 \mathrm{mg} \text {, } \\
\text { that could be increased } \\
\text { by the physician to } 0.25 \text {, } \\
0.50 \text { or } 0.75 \mathrm{mg} / \mathrm{day} \text {. } \\
\text { - } 2-3 \text { hours before } \\
\text { bedtime }\end{array}$ & $\begin{array}{l}\text { - Primary outcome: IRLS } \downarrow \\
\text { - Secondary outcome: } \\
\text { Improvement in PGI, CGI,VAS }\end{array}$ \\
\hline $\begin{array}{l}\text { Trenkwalder } \\
2006^{57}\end{array}$ & $\begin{array}{l}\text { Multicenter, double-blind, randomized, } \\
\text { flexible-dose, placebo-controlled } \\
\text { withdrawal trial. } \\
\text { - Randomization: I:I } \\
\text { - I50 RLS patients responding to } \\
\text { pramipexole on a six-month period } \\
\text { were randomly assigned to receive } \\
\text { placebo or to continue pramipexole } \\
\text { for three months }\end{array}$ & $\begin{array}{l}\text { Individual optimized } \\
\text { dosage }(0.125,0.25 \text {, } \\
0.50 \text { or } 0.75 \mathrm{mg} / \mathrm{die}) \text {. } \\
\text { - } 2-3 \text { hours before } \\
\text { bedtime }\end{array}$ & $\begin{array}{l}\text { - Primary outcome: } \\
\text { I) CGI-I score of minimally, much or } \\
\text { very much worse } \downarrow \downarrow \text { in pramipexole } \\
\text { group (less than } 50 \% \text { reached the } \\
\text { target event). } \\
\text { 2) An increase of IRLS to a score > I5. } \\
\text { } \uparrow \text { in Placebo group. } \\
\text { - Secondary outcome: } \\
\text { CGI-I } \uparrow ; \text { CGI-S } \downarrow \downarrow ; \text { CGI-E } \uparrow \uparrow ; \text { PGI } \uparrow \text {; } \\
\text { RLS-QOL } \uparrow\end{array}$ \\
\hline $\begin{array}{l}\text { Montplaisir } \\
2006^{55}\end{array}$ & $\begin{array}{l}\text { - Telephone interview. } \\
\text { - } 195 \text { consecutives patients with } \\
\text { idiopathic RLS who underwent } \\
\text { pramipexole treatment for at least } \\
\text { one year }\end{array}$ & $\begin{array}{l}\text { - Mean dose }=0.59 \\
\pm 0.31 \mathrm{mg}(\text { range }= \\
0.125-2.25 \mathrm{mg}) \\
\text { - } \text { Mean treatment } \\
\text { duration }= \\
30.5 \pm 10.5 \text { months }\end{array}$ & $\begin{array}{l}\text { Questionnaire on efficacy: } \\
\text { - RLS severity } \downarrow \downarrow \\
\text { - Difficulty in falling asleep } \downarrow \downarrow \\
\text { - Nocturnal awakenings } \downarrow \downarrow\end{array}$ \\
\hline Manconi $2007^{43}$ & $\begin{array}{l}\text { - Single-blind, randomized, placebo- } \\
\text { controlled, fixed-dose trial. } \\
\text { - Randomization: I:I } \\
\text { - } 32 \text { patients with severe idiopathic } \\
\text { RLS, never previously treated for RLS } \\
\text { - Comparison of clinical and neuro- } \\
\text { physiological parameters at the base- } \\
\text { line and after one night treatment. }\end{array}$ & $\begin{array}{l}\text { - Single dose of } 0.25 \mathrm{mg} \\
\text { - Administration } \\
\text { time }=9.00 \text { p.m. }\end{array}$ & $\begin{array}{l}\text { - Primary outcome: } \\
\text { - PLMS change index: } \downarrow \\
\text { - Secondary outcome: } \\
\text { - Sleep stage } 2 \uparrow ; \text { time in bed, sleep } \\
\text { efficiency }(\uparrow) \\
\text { VAS (severity) }=\downarrow \downarrow\end{array}$ \\
\hline Partinen $2008^{54}$ & $\begin{array}{l}\text { - Open label trial } \\
\text { - } 26 \text { week period }\end{array}$ & $\begin{array}{l}\text { - Initial dose }=0.125 \mathrm{mg} \\
\text { (titrated up to a } \\
\text { maximum } 0.75 \mathrm{mg} \text { ) } \\
\text { - Administration time = } \\
8.00-9.00 \text { p.m. }\end{array}$ & $\begin{array}{l}\text { - Primary outcome: IRLS } \downarrow \\
\text { - Secondary outcome: } \\
\text { Improvement in CGI-I; PGI-I; ESS; } \\
\text { SF-36; SSQ }\end{array}$ \\
\hline
\end{tabular}

(Continued) 
Table 3 (Continued)

\begin{tabular}{|c|c|c|c|}
\hline & Study design & $\begin{array}{l}\text { Pramipexole } \\
\text { administration }\end{array}$ & Outcome measure \\
\hline $\begin{array}{l}\text { Ferini-Strambi } \\
2008^{52}\end{array}$ & $\begin{array}{l}\text { - Double-blind, randomized, placebo- } \\
\text { controlled, flexible-dose trial. } \\
\text { - Randomization: I:I } \\
\text { - } 357 \text { patients with moderate-severe } \\
\text { idiopathic RLS } \\
\text { - } 12 \text { week period }\end{array}$ & $\begin{array}{l}\text { - Initial dose }=0.125 \\
\mathrm{mg} \text { (titrated up to a } \\
\text { maximum } 0.75 \mathrm{mg} \text { ). } \\
\text { - } 2-3 \text { hours before } \\
\text { bedtime }\end{array}$ & $\begin{array}{l}\text { - Primary outcome: } \\
\text { I) IRLS } \downarrow \\
\text { 2) MOS scale-sleep disturbance (initiation } \\
\text { and maintenance) domain. } \downarrow \downarrow \\
\text { - Secondary outcome: } \\
\text { Improvement in CGI-I; PGI-I; RLS-QOL }\end{array}$ \\
\hline
\end{tabular}

Abbreviations: $\uparrow$, significantly increased; $\uparrow \uparrow$, highly significantly increased; ( $\uparrow$ ), increased but not significantly; $\rightarrow$, unchanged; $\downarrow$, significantly decreased; $\downarrow \downarrow$, highly significantly decreased; $(\downarrow)$, decreased but not significantly; PLMI, periodic limb movement during time in bed index; PLMSI, periodic limb movement during sleep index; PLMWI, periodic limb movement during wakefulness index; PLMAI, periodic limb movement during sleep with arousal index; PLM, total number of periodic limb movements; PLMS, total number of periodic limb movements during sleep; PLMA, total number of periodic limb movements during sleep with arousal; SL, sleep latency; SE, sleep efficiency; TST, total sleeping time; sREM, stage rapid eye movement sleep; RLS, restless legs syndrome; IRLS, International Restless Legs Syndrome scale total score; ESS, Epworth Sleepiness Scale; SSQ, subjective sleep quality scale;SF-36, Short Form 36 Health Survey Questionnaire PGI,Patient Global Impression scale; CGI, Clinical Global Impression scale; CGI-I, Glinical Global Impression Improvement scale; CGI-S, Clinical Global Impression - Severity scale; CGI-E, Clinical Global Impression - Efficacy scale; VAS, visual analogue scale; RLS-QOL, Johns Hopkins Restless Legs Syndrome Quality Of Life Questionnaire; SSQ, subjective sleep quality.

The incidence of adverse events was higher in the pramipexole group than in the placebo group, but not clearly dose-related. The most frequent adverse event was nausea, followed by fatigue, dizziness, headache, diarrhea, and nasopharyngitis, orthostatic hypotension and increased body weight. The severity of side effects was usually mildto-moderate. An emerging concern with dopamine agonists is represented by compulsive behaviors, and in particular gambling. ${ }^{57}$

The prevalence of side effect seems to decrease significantly in long-term treatment (2.6\%) (55 ddd) compared with early treatment.

\section{Opioids}

Opioids are used with increasing frequency in RLS therapy, especially in patients with significant daily symptoms and refractory RLS. However, only a few trials are available, concerning oxycodone (mean dose $15.9 \mathrm{mg}$ ), ${ }^{58}$ methadone $(15.5 \pm 7.7 \mathrm{mg} /$ day $),{ }^{59}$ tramadol $(50-150 \mathrm{mg} /$ day $){ }^{60}$ Although likely efficacious, they may cause a series of minor and major adverse effects: dizziness, nausea, vomiting, urinary retention, and constipation. Respiratory depression and addiction potential are major concerns. Augmentation has been reported with long-term tramadol treatment. $^{61}$

\section{Conclusions}

RLS seems to be a quite common condition, although probably overlooked, and it may be disabling in severe cases. Thus improved diagnostic knowledge of RLS is warranted, in order to improve quality of life using available effective treatments in primary RLS, and, in addition, to individuate and treat underlying diseases in secondary RLS.
The mainstay of symptomatic treatment is represented by dopamine agonists, and in particular nonergot-derived. In this respect, available data suggest better efficacy and tolerability of pramipexole.

\section{Disclosure}

The authors report no conflicts of interest in this work.

\section{References}

1. Willis T. De anima brutorum qua hominis vitalis ac sensitiva est, excertitationes duce; prior physiologica ejusdem naturam, partes, potentias et affectiones tradit; altera pathologica morbos qui ipsam, et sedem ejus primarium, nempe ceerebrum et nervosum genus atticiunt, explicat, eorumque therapeias instituit. Oxford, two editions 1672 (quarto and octavo); London, R. Davis, 1672; Amsterdam, 1672, 1674; Lyon, 1676.

2. Allen RP, Picchietti D, Hening WA, Trenkwalder C, Walters AS, Montplaisir J; Restless Legs Syndrome Diagnosis and Epidemiology workshop at the National Institutes of Health; International Restless Legs Syndrome Study Group. Restless legs syndrome: diagnostic criteria, special considerations, and epidemiology. A report from the restless legs syndrome diagnosis and epidemiology workshop at the National Institutes of Health. Sleep Med. 2003;4(2):101-119.

3. Walters AS. Toward a better definition of the restless legs syndrome. The International Restless Legs Syndrome Study Group. Mov Disord. 1995;10(5):634-642.

4. Berger K, Kurth T. RLS epidemiology,frequencies, risk factors and methods in population studies. Mov Disord. 2007;22 Suppl 18: S420-S423.

5. Allen RP, Walters AS, Montplaisir J, et al. Restless legs syndrome prevalence and impact: REST general population study. Arch Intern Med. 2005;165(11):1286-1292.

6. Tan EK, Seah A, See SJ, Lim E, Wong MC, Koh KK. Restless legs syndrome in an Asian population: A study in Singapore. Mov Disord. 2001;16(3):577-579.

7. Mizuno S, Miyaoka T, Inagaki T, Horiguchi J. Prevalence of restless legs syndrome in non-institutionalized Japanese elderly. Psychiatry Clin Neurosci. 2005;59(4):461-465.

8. Earley CJ, Connor JR, Beard JL, Malecki EA, Epstein DK, Allen RP. Abnormalities in CSF concentrations of ferritin and transferrin in restless legs syndrome. Neurology. 2000;54(8):1698-1700.

9. Winkelman JW, Chertow GM, Lazarus JM. Restless legs syndrome in end-stage renal disease. Am J Kidney Dis. 1996;28(3):372-378. 
10. Manconi M, Govoni V, De Vito A, et al. Restless legs syndrome and pregnancy. Neurology. 2004;63(6):1065-1069.

11. Hening WA, Caivano CK. Restless legs syndrome: a common disorder in patients with rheumatologic conditions. Semin Arthritis Rheum. 2008;38(1):55-62.

12. Gemignani F, Brindani F, Marbini A. Restless legs syndrome and polyneuropathy in rheumatologic diseases. Semin Arthritis Rheum. 2009;38(4):336.

13. Merlino G, Fratticci L, Valente M, et al. Association of restless legs syndrome in type 2 diabetes: a case-control study. Sleep. 2007;30(7):866-871.

14. Gemignani F, Brindani F, Vitetta F, Marbini A, Calzetti S. Restless legs syndrome in diabetic neuropathy: a frequent manifestation of small fiber neuropathy. J Peripher Nerv Syst. 2007;12(1):50-53.

15. Iranzo A, Comella CL, Santamaria J, Oertel W. Restless legs syndrome in Parkinson's disease and other neurodegenerative diseases of the central nervous system. Mov Disord. 2007;22 Suppl 18:S424-S430.

16. Clemens S, Rye D, Hochman S. Restless legs syndrome: revisiting the dopamine hypothesis from the spinal cord perspective. Neurology. 2006;67(1):125-130.

17. Italian REMS Study Group; Manconi M, Ferini-Strambi L, Filippi M, et al. Multicenter case-control study on restless legs syndrome in multiple sclerosis: the REMS study. Sleep. 2008;31(7):944-952.

18. Gemignani F, Brindani F, Negrotti A, Vitetta F, Alfieri S, Marbini A. Restless legs syndrome and polyneuropathy. Mov Disord. 2006;21(8):1254-1257.

19. Rutkove SB, Matheson JK, Logigian EL. Restless legs syndrome in patients with polyneuropathy. Muscle Nerve. 1996;19(5):670-672.

20. Nineb A, Rosso C, Dumurgier J, Nordine T, Lefaucheur JP, Créange A. Restless legs syndrome is frequently overlooked in patients being evaluated for polyneuropathies. Eur J Neurol. 2007;14(7): 788-792.

21. Hattan E, Chalk C, Postuma RB. Is there a higher risk of restless legs syndrome in peripheral neuropathy? Neurology. 2009;72(11):955-960.

22. Iannaccone $S, Z$ Zucconi $M, M a r c h e t t i n i ~ P$, et al. Evidence of peripheral axonal neuropathy in primary restless legs syndrome. Mov Disord. 1995;10:2-9.

23. Polydefkis M, Allen RP, Hauer P, Earley CJ, Griffin JW, McArthur JC. Subclinical sensory neuropathy in late-onset restless legs syndrome. Neurology. 2000;55(8):1115-1121.

24. Schattschneider J, Bode A, Wasner G, Binder A, Deuschl G, Baron R. Idiopathic restless legs syndrome: abnormalities in central somatosensory processing. J Neurol. 2004;251(8):977-982.

25. Gemignani F, Brindani F, Marbini A. Restless legs syndrome and diabetic neuropathy. Sleep. 2008;31(3):307.

26. Winkelman JW. Considering the causes of RLS. Eur J Neurol. 2006;3:8-14.

27. Akpinar S. Restless legs syndrome treatment with dopaminergic drugs. Clin Neuropharmacol. 1987;10(1):69-79.

28. Paulus W, Dowling P, Rijsman R, Stiasny-Kolster K, Trenkwalder C. Update of the pathophysiology of the restless-legs-syndrome. Mov Disord. 2007;22 Suppl 18:S431-S439.

29. Trotti LM, Bhadriraju S, Rye DB. An update on the pathophysiology and genetics of restless legs syndrome. Curr Neurol Neurosci Rep. 2008;8(4):281-287.

30. Trenkwalder C, Hening WA, Montagna P, et al. Treatment of restless legs syndrome: an evidence-based review and implications for clinical practice. Mov Disord. 2008;23(16):2267-2302.

31. von Spiczak S, Whone AL, Hammers A, et al. The role of opioids in restless legs syndrome: an [11C]diprenorphine PET study. Brain. 2005;128(Pt 4):906-917.

32. The Atlas Task Force of the American Sleep Disorders Associations. Recording and scoring leg movements. The Atlas Task Force. Sleep. 1993;16:748-759.

33. Montplaisir J, Boucher S, Poirier G, Lavigne G, Lapierre O, Lespérance P. Clinical, polysomnographic, and genetic characteristics of restless legs syndrome: a study of 133 patients diagnosed with new standard criteria. Mov Disord. 1997;12(1):61-65.
34. Allen RP, Earley CJ. Restless legs syndrome: a review of clinical and pathophysiologic features. J Clin Neurophysiol. 2001;18(2):128-147.

35. Aksu M, Demirci S, Bara-Jimenez W. Correlation between putative indicators of primary restless legs syndrome severity. Sleep Med. 2007;8(1):84-89.

36. Benes H, Walters AS, Allen RP, Hening WA, Kohnen R. Definition of restless legs syndrome, how to diagnose it, and how to differentiate it from RLS mimics. Mov Disord. 2007; 22 Suppl 18:S401-S408.

37. Gemignani F, Brindani F. Restless legs syndrome associated with peripheral neuropathy. Eur J Neurol. 2007;14(7):e9-e10.

38. Merlino G, Serafini A, Gigli GL. Response to restless legs syndrome and diabetic neuropathy-commentary by Gemignani et al. Sleep . 2008;31(8):1069.

39. Vignatelli L, Billiard M, Clarenbach P, et al; EFNS Task Force. EFNS guidelines on management of restless legs syndrome and periodic limb movement disorder in sleep. Eur J Neurol. 2006;13(10):1049-1065.

40. García-Borreguero D, Allen RP, Kohnen R, et al; International Restless Legs Syndrome Study Group. Diagnostic standards for dopaminergic augmentation of restless legs syndrome: report from a World Association of Sleep Medicine-International Restless Legs Syndrome Study Group consensus conference at the Max Planck Institute. Sleep Med. 2007;8(5):520-530.

41. Chitnis S. Ropinirole treatment for restless legs syndrome. Expert Opin Drug Metab Toxicol. 2008;4(5):655-664

42. Oertel WH, Trenkwalder C, Zucconi M, et al. State of the art in restless legs syndrome therapy: practice recommendations for treating restless legs syndrome. Mov Disord. 2007;22 Suppl 18:S466-S475.

43. Manconi M, Ferri R, Zucconi M, et al. First night efficacy of pramipexole in restless legs syndrome and periodic legs movements. Sleep Med. 2007;8(5):491-497.

44. Quilici S, Abrams KR, Nicolas A, et al. Meta-analysis of the efficacy and tolerability of pramipexole versus ropinirole in the treatment of restless legs syndrome. Sleep Med. 2008;9:715-726.

45. Montplaisir J, Nicolas A, Denesle R, Gomez-Mancilla B. Restless legs syndrome improved by Pramipexole: a doule blind randomized trial. Neurology. 1999;52:938-943

46. Montplaisir J, Denesle R, Petit D. Pramipexole in the treatment of restless legs syndrome: a follow-up study. Eur J Neurol. 2000; 7(Suppl 1):27-31.

47. Lin SC, Kaplan J, Burger CD, Fredrickson PA. Effect of pramipexole in treatment of resistant restless legs syndrome. Mayo Clin Proc. 1998;73:497-500.

48. Becker PM, Ondo W, Sharon D. Encouraging initial response of restless legs syndrome to pramipexole. Neurology. 1998;51:1221-1223.

49. Stiasny-Kolster K, Oertel WH. Low-dose pramipexole in the management of restless legs syndrome. Neuropsychobiology. 2004; 50:65-70.

50. Winkelman JW, Sethi KD, Kushida CA, et al. Efficacy and safety of pramipexole in restless legs syndrome. Neurology. 2006; 67:1034-1039.

51. Oertel WH, Stiasny-Kolster K, Bergtholdt B, et al; Pramipexole RLS Study Group. Efficacy of pramipexole in restless legs syndrome: a sixweek, multicenter, randomized, double-blind study (effect-RLS study). Mov Disord. 2007;22(2):213-219.

52. Ferini Strambi L, Aarskog D, Partinen M, et al. Effect of pramipexole on RLS symptoms and sleep: A randomized, double-blind, placebocontrolled trial. Sleep Med. 2008;9:874-881.

53. Partinen M, Hirvonen K, Jama L, et al. Efficacy and safety of Pramipexole in idiopathic restless legs syndrome: A polysomnographic dosefinding study - The PRELUDE study. Sleep Med. 2006;7:407-417.

54. Partinen M, Hirvonen K, Jama L, et al. Open-label study of the long-term efficacy and safety of Pramipexole in patients with Restless Legs Syndrome (extension of the PRELUDE study). Sleep Med. 2008;9(5):537-541.

55. Montplaisir J, Fantini ML, Desautels A, Michaud M, Petit D, Filipini D. Long-term treatment with pramipexole in restless legs syndrome. Eur J Neurol. 2006;13(12):1306-1311. 
56. Trenkwalder C, Stiasny-Kolster K, Kupsch A, Oertel WH, Koester J, Reess J. Controlled withdrawal of pramipexole after 6 months of openlabel treatment in patients with restless legs syndrome. Mov Disord. 2006;21(9):1404-1410.

57. Driver-Dunckley ED, Noble BN, Hentz JG, et al. Gambling and increased sexual desire with dopaminergic medications in restless legs syndrome. Clin Neuropharmacol. 2007;30(5):249-255.

58. Walters AS, Wagner ML, Hening WA, et al. Successful treatment of the idiopathic restless legs syndrome in a randomized double-blind trial of oxycodone versus placebo. Sleep. 1993;16:327-332.
59. Ondo WG. Methadone for refractory restless legs syndrome. Mov Disord. 2005;20:345-348.

60. Lauerma H, Markkula J. Treatment of restless legs syndrome with tramadol: an open study. J Clin Psychiatry. 1999;60:241-244.

61. Vetrugno R, La Morgia C, D’Angelo R, et al. Augmentation of restless legs syndrome with long-term tramadol treatment. Mov Disord. 2007; 22:424-427.

\section{Publish your work in this journal}

Clinical Interventions in Aging is an international, peer-reviewed journal focusing on evidence-based reports on the value or lack thereof of treatments intended to prevent or delay the onset of maladaptive correlates of aging in human beings. This journal is indexed on PubMed Central, MedLine, the American Chemical Society's 'Chemical

\section{Dovepress}

Abstracts Service' (CAS), Scopus and the Elsevier Bibliographic databases. The manuscript management system is completely online and includes a very quick and fair peer-review system, which is all easy to use. Visit http://www.dovepress.com/testimonials.php to read real quotes from published authors.

Submit your manuscript here: http://www.dovepress.com/clinical-interventions-in-aging-journal 